IZA DP No. 6511

\title{
Equilibrium Unemployment and Retirement
}

Jean-Olivier Hairault

François Langot

André Zylberberg

April 2012 


\title{
Equilibrium Unemployment and Retirement
}

\author{
Jean-Olivier Hairault \\ PSE, University of Paris 1 \\ and IZA \\ François Langot \\ PSE, GAINS-TEPP, University of Maine
}

and IZA

André Zylberberg

University of Paris 1, CNRS

Discussion Paper No. 6511

April 2012

IZA

P.O. Box 7240

53072 Bonn

Germany

Phone: +49-228-3894-0

Fax: +49-228-3894-180

E-mail: iza@iza.org

Any opinions expressed here are those of the author(s) and not those of IZA. Research published in this series may include views on policy, but the institute itself takes no institutional policy positions.

The Institute for the Study of Labor (IZA) in Bonn is a local and virtual international research center and a place of communication between science, politics and business. IZA is an independent nonprofit organization supported by Deutsche Post Foundation. The center is associated with the University of Bonn and offers a stimulating research environment through its international network, workshops and conferences, data service, project support, research visits and doctoral program. IZA engages in (i) original and internationally competitive research in all fields of labor economics, (ii) development of policy concepts, and (iii) dissemination of research results and concepts to the interested public.

IZA Discussion Papers often represent preliminary work and are circulated to encourage discussion. Citation of such a paper should account for its provisional character. A revised version may be available directly from the author. 
IZA Discussion Paper No. 6511

April 2012

\section{ABSTRACT}

\section{Equilibrium Unemployment and Retirement ${ }^{\star}$}

As a preliminary step, we first provide some new empirical evidence that labor market conditions affect retirement decisions at the individual level: unemployed people are more likely to retire. Our main objective in this paper is then to propose an equilibrium unemployment approach to retirement decisions that allows us to unveil the factors which explain why unemployed workers choose to retire earlier and the conditions under which this behavior is optimal. Two main conclusions emerge: the retirement decision of unemployed workers depends on the labor-market frictions whereas that of employed workers does not; the existence of search externalities makes the retirement age of unemployed workers intrinsically suboptimal. Considering Social Security policy issues, we show that the complete elimination of the implicit tax on continued activity is not necessarily welfare-optimizing in a second best world where the labor market equilibrium suffers from distortions.

JEL Classification: J22, J26, H55

Keywords: search, matching, retirement, Social Security

Corresponding author:

Jean-Olivier Hairault

Université Paris 1 Panthéon-Sorbonne

CES-Centre d'Economie de la Sorbonne

Maison des Sciences Eco.

106-112 boulevard de l'Hôpital

75647 Paris Cedex 13

France

E-mail: joh@univ-paris1.fr

\footnotetext{
* Financial support through Cepremap is gratefully acknowledged. We thank Y. Fawaz for excellent research assistance.
} 


\section{Introduction}

Labor market conditions have been surprisingly overlooked as a determinant of retirement decisions. Much of the existing literature on retirement has focused on the effect of health conditions and Social Security provisions (Gustman and Steinmeir (2002), French (2005)). The labor market status has been ignored until now. One notable exception is the recent empirical analysis of Coile and Levine (2006) who have empirically shown that changes in the unemployment rate affects the average retirement age and that the magnitude of this effect can be considered as comparable to that associated with realistic changes in financial incentives to retire. The recent great recession with the subsequent huge increase in unemployment would have led to a decline in the average retirement age (Coile and Levine (2012)). As this surge in older worker unemployment can be considered to some extent as exogenous from worker decisions, due to involuntary lay-offs, being unemployed per se, and not as the reflection of the higher disutility of working or of bad health, can be viewed as being responsible for earlier retirement.

In this paper, we put forward the idea that unemployed workers choose to retire earlier than employed workers as the consequence of labor-market frictions. The intuition is straightforward: as far as there exist search frictions on the labor market, the value of being employed is always higher than that of being unemployed. Unemployed workers therefore choose to retire earlier because their welfare prospects on the labor market are lower than those of employed workers. A part of the observed heterogeneity in terms of retirement age can be explained by the difference of incentives to retire between employed and unemployed workers. Whereas the retirement decision of employed workers is governed by the labor supply side, that of unemployed workers is subject to the labor market equilibrium and the potential inefficiencies it generates in a search-friction environment. This paper is the first contribution that shows how labor market conditions affect retirement decisions and policies.

First, we propose some new empirical evidence on the fact that the labor market conditions matter for the retirement decision at the individual level, independently of other individual characteristics: we investigate whether unemployed workers retire before employed workers, other things being equal. We use the HRS (Health and Retirement Study) dataset in order to have very detailed information on health and socio-economic variables. We study the impact of searching during one wave on the probability of retiring by the next wave by estimating probit equations. It appears that looking for a job (compared to working) increases the probability of retiring by $18.8 \%$.

Secondly, our main objective in this paper is then to propose an equilibrium unemployment approach to retirement decisions that allows us to derive the positive and normative features of retirement decisions when search and matching frictions are considered. We aim to unveil the factors which explain why unemployed workers choose to retire earlier and the conditions under 
which this behavior is optimal. The equilibrium unemployment theory à la Pissarides (2000), once life-cycle features are considered, naturally delivers the conclusion that labor market status matters for retirement decisions. An important implication of our theory is that the retirement decision of unemployed workers depends on the labor market tightness whereas that of employed workers does not. Once unemployed workers choose to retire, the wages of still-employed workers are not indexed on the labor market tightness, as their threat point is the retirement opportunity. On the contrary, the retirement decision for unemployed workers relies on the labor market tightness because the latter determines the expected employment value. The higher the search frictions, the sooner the retirement age for unemployed people, relative to that of employed workers. The retirement gap between unemployed and employed workers is then determined by the magnitude of the search frictions. Moreover, the retirement age of employed workers influences that of unemployed workers through the labor market tightness. A short horizon makes the labor market search costs difficult to recoup when the retirement age of the employed workers is imminent. This thesis has already received some empirical support (Hairault, Langot and Sopraseuth (2010)) and some theoretical foundation based on the job search theory (Seater (1977), Ljungqvist and Sargent (2008) and Hairault, Langot and Sopraseuth (2010)). In this paper, we generalize this view to the labor-market equilibrium approach.

The fundamental asymmetry across workers according to their labor market status at the market equilibrium has important implications for the optimality of the decentralized retirement decisions. Once search frictions are considered, it is straightforward to calculate that it is optimal that unemployed workers retire before the employed workers. The matching technology makes the recruiting process costly, especially when the expected career time is short. However, the magnitude of the retirement age gap is not necessarily optimal; it depends on the degree of inefficiency conveyed by the labor market. The existence of search externalities makes the retirement age of unemployed workers suboptimal, except when the Hosios condition holds. The retirement of unemployed individuals can happen either too soon or too late, for a given retirement age of employed workers, depending on the number of vacancies that are created by firms at the equilibrium. On the other hand, as the retirement decision of employed workers is independent of the labor market tightness, their decision is not distorted by the search externalities. This leads to propose pension adjustments specific to workers, according to their labor market status. Besides, actuarially-fair pension adjustments are no longer optimal when search externalities distort the labor-market equilibrium.

Our paper is the first contribution that addresses the issue of the retirement decision with matching frictions in a life-cycle environment. It relates the job creation and participation decisions on the one hand to the retirement decisions of unemployed and employed workers on the other hand. This clearly extends the analysis of Hairault, Langot and Sopraseuth (2010) led by a partial equilibrium job search model. We share with Garibaldi and Wasmer (2005) the same emphasis on the search frictions for the participation decision of the unemployed workers. 
Whereas they consider a stochastic framework arising from shocks on home productivity, we adopt a deterministic overlapping generation model where the participation decision coincides with the retirement decision. We then focus on the importance of the labor market frictions for retirement and Social Security issues. We then extend to endogenous retirement decisions the analysis led by Cheron, Hairault and Langot (2011) in a life-cycle matching model. We depart from this latter paper by focusing on the retirement specificity of the unemployed workers relative to employed workers in an otherwise efficient search process. In particular, we leave aside the intergenerational inefficiencies that arise from the age heterogeneity of workers when the search is not age-directed. This is why the Hosios condition ensures the optimality of retirement decisions in our theoretical framework. ${ }^{1}$

Our paper is organized as follows. We first investigate the empirical contribution of the unemployed status, more especially of searching for a job, to the individual decision of retirement, with respect to traditional individual characteristics. In a second section, we present a canonical matching model with age-heterogeneity and endogenous retirement.

\section{Some empirical evidence based on individual data}

In this section, we propose some empirical evidence for the fact that unemployed workers retire before employed workers. We use the Health and Retirement Study (HRS) dataset in order to have very detailed information on health and socio-economic variables. It surveys Americans over the age of 50 every two years. We therefore study the labor market transitions every two years, which is a clear limit of using this dataset. Due to unobserved heterogeneity across individuals, which could matter for both unemployment and retirement status (i.e. higher preference for leisure for instance), we acknowledge that this evidence cannot be interpreted in a causal sense. However, the use of subjective data available in the HRS dataset will allow us to seriously address the unobserved heterogeneity issue. Especially, the self-estimated probability of continuing to work full-time after age 62 or 65 will be used to reveal different tastes for leisure or a lesser attachment to work. $^{2}$

\footnotetext{
${ }^{1}$ On the other hand, Albrecht, Navarro and Vroman (2010) show that in a search/matching model with endogenous participation in which workers are heterogeneous with respect to market productivity, satisfying the Hosios rule leads to excessive vacancy creation.

${ }^{2}$ This variable is the self-estimated probability of continuing to work full-time after 62 if the individual is aged less than 62 , and the corresponding probability of working full-time after 65 if aged over 62 . When these variables were missing because the individual was not working at that time we imputed the closest non-missing value from previous waves.
} 


\subsection{Descriptive analysis}

We first present the information we use on the labor force status, especially on the partially retired status, which is a dominant one as far as age goes.

\subsubsection{Labor force status: elements of definition}

The labor force variable in the HRS dataset ("RLBRF") summarizes the labor force status of the respondent at each wave as working full-time, working part-time, unemployed, partly retired (explanatory variables), retired (dependent variable), disabled, or not in the labor force (omitted variables).

If the respondent is working part-time and does not mention retirement, his status is set to "works part-time". In our sample, made up of individuals aged 55 to 65, full-time workers report working 45 hours a week on average, compared to a 25 hour working week for part-time workers. Full-time work ( $41 \%$ of the sample) is defined as working at least 35 hours per week, at least 36 weeks per year. Less than this is considered part-time work ( $8 \%$ of the sample). If the respondent is not working but is looking for a full-time or a part-time job, then he is set to unemployed, provided that there is no mention of retirement. Our data confirms that 100 per cent of unemployed respondents do report that they are looking for a job. These individuals represent hardly more than $1.4 \%$ of the sample. If the respondent is working part-time and reports being retired at the same time, his status is set to "partly retired" (this is the case for $8 \%$ of the sample). If he is not working but currently looking for a job, and mentions retirement, his status is set to "partly retired" too. Thus partly retired respondents are either working part-time and retired, or looking for a job and retired, but in both cases, they are still "active" individuals. In our sample, $92 \%$ of partly retired individuals are working, with an average of 19 hours per week; 8 per cent are looking for a job. If the respondent is neither working nor looking for a job, and mentions retirement, then he is "retired" ( $28 \%$ of the sample). If he is neither working nor looking for a job, but mentions disability, his status is set to "disabled". Their share in the sample is $5 \%$. Otherwise, if the respondent is not working, not looking for a job, and neither retired nor disabled, his status is set to "out of the labor force". This category is almost entirely made up of women (95\%), and represents 9 per cent of the sample. Disabled and "out of the labor force" individuals do not fit into our theoretical model, so that there is no reason to include them hereafter.

Figure 1 graphs the labor force status of the pooled sample by age. As individuals age, they are decreasingly full-time or part-time workers and increasingly retired. Since "part-time workers" and "partly retired" individuals who are working both work part-time, their curves are roughly symmetric: that of part-time workers plummets while that of "partly retired workers" goes up, so that the two curves cross at age 61 , when many part-time workers begin to call themselves 
Table 1: Summary statistics on labor force status by gender

\begin{tabular}{|c|c|c|c|c|c|c|}
\hline \multirow{3}{*}{$\begin{array}{l}\text { labor force status } \\
\text { Working full-time }\end{array}$} & \multicolumn{6}{|c|}{ gender } \\
\hline & \multicolumn{2}{|c|}{ male } & \multicolumn{2}{|c|}{ female } & \multicolumn{2}{|c|}{ Total } \\
\hline & 13,267 & 51.75 & 10,135 & 32.80 & 23,402 & 41.39 \\
\hline Working part-time & 1,074 & 4.19 & 3,397 & 10.99 & 4,471 & 7.91 \\
\hline Unemployed & 397 & 1.55 & 382 & 1.24 & 779 & 1.38 \\
\hline Partly retired & 2,313 & 9.02 & 2,139 & 6.92 & 4,452 & 7.87 \\
\hline Retired & 7,229 & 28.20 & 8,385 & 27.13 & 15,614 & 27.62 \\
\hline Disabled & 1,112 & 4.34 & 1,621 & 5.25 & 2,733 & 4.83 \\
\hline Not in labor force & 243 & 0.95 & 4,845 & 15.68 & 5,088 & 9.00 \\
\hline Total & 25,635 & 100.00 & 30,904 & 100.00 & 56,539 & 100.00 \\
\hline
\end{tabular}

Figure 1: Distribution of labor force status by age

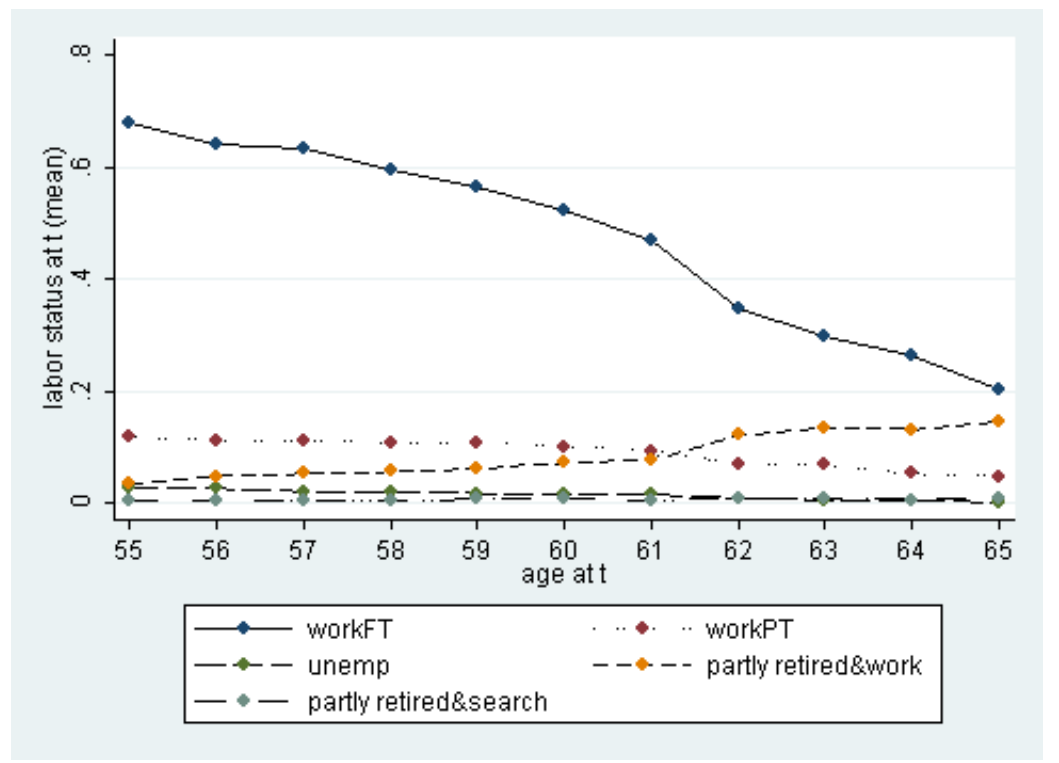


retirees even if they are still working part-time.

\subsubsection{Partly retired individuals $v$. their searching and working counterparts}

Within the five categories of individuals that fit into the model, one is particularly hard to define. Indeed the partly retired are far from being a homogeneous group as most of them are working part-time while some are looking for a job. Before going further with the impact of the job search on retirement, it seems necessary to understand what characteristics are specific to partly retired working individuals compared to part-time workers, and on the other hand what makes partly retired searchers different from their unemployed counterparts.

In the following tables we look at individual characteristics for part-time workers and retired part-time workers in order to understand what could bring them to mention a retirement status while still working (see Table 2). Likewise, we compare the partly retired who do not work but search, to the unemployed who make no mention of retirement, over a smaller set of variables excluding job characteristics (see Table 3).

Table 2: Characteristics of part-time workers v. partly retired workers

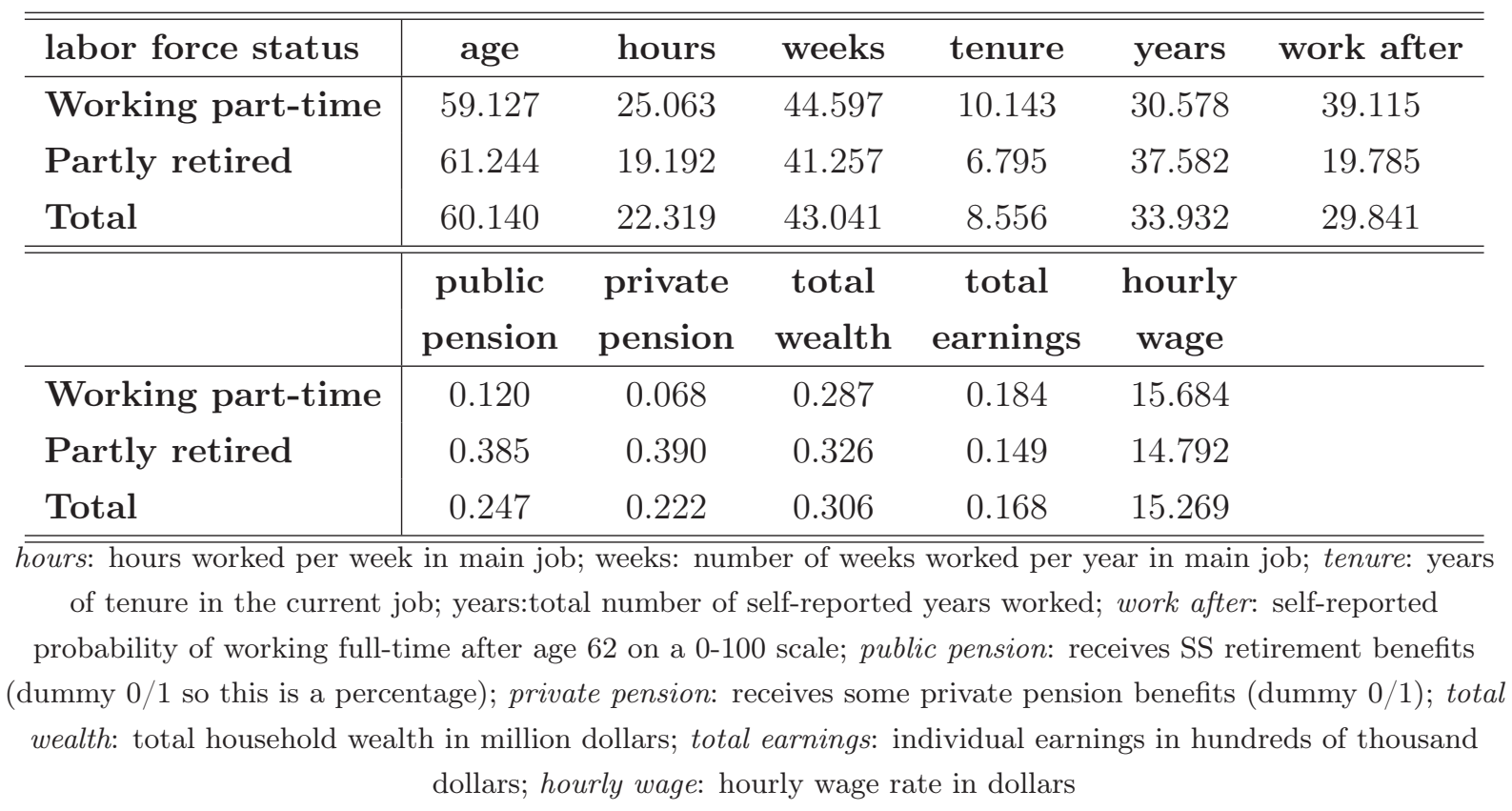

Table 2 displays the main characteristics of these two types of workers. They seem to differ mostly in their self-estimated probability of continuing to work full-time after age 62 or 65, which is $39 \%$ for part-time workers against only $20 \%$ for partly-retired workers. Also $39 \%$ of the partly retired receive income from a private pension plan, which is the case for only $7 \%$ of part-time workers, and the same goes for Social Security benefits. Thus partly retired individuals 
already feel retired as they think they are more likely not to work full time after a given age and many of them already get some pension income. Partly retired individuals may then have a greater taste for leisure or a lesser attachment to work, which is revealed by their expectations about their future at work. This is why this subjective variable will be used to deal with the unobserved individual heterogeneity in terms of preferences for leisure.

The two groups do not differ very much in their working pattern. Indeed partly retired workers work fewer hours per week (less than 20 compared to over 25 for part-time workers), fewer weeks per year and their hourly wage is very close to that of part-time workers, so that their total earnings from work are slightly inferior. They have a longer job history than part-time workers (38 worked years compared to 31 for part-time workers) but less tenure in their current job (7 v. 10 years). Hence many partly retired individuals seem to be part-time workers who have already left their longest-tenure job and get the associated pension. Or, they have reduced the number of hours they used to work and are not willing to go back to full-time employment one day. Consequently they consider themselves as retired in some way, but their job characteristics are quite close to those of their counterparts who do not report any retirement status.

Table 3: Characteristics of unemployed v. partly retired searchers

\begin{tabular}{l|ccccccc}
\hline \hline & & & work & public & private & total & $\begin{array}{c}\text { total } \\
\text { labor force status }\end{array}$ \\
age & years & after & pension & pension & wealth & earnings \\
\hline Unemployed & 58.266 & 29.080 & 54.223 & 0.060 & 0.089 & 0.166 & 0.202 \\
Partly ret & 60.580 & 34.055 & 30.586 & 0.284 & 0.304 & 0.206 & 0.138 \\
Total & 58.977 & 30.608 & 45.084 & 0.129 & 0.155 & 0.178 & 0.182 \\
\hline \hline
\end{tabular}

Comparing the unemployed to the partly retired who are looking for a job yields similar findings. The partly retired have a longer job history than the unemployed, but the main discrepancies come from their expectations about their probability of continuing full-time work ( $54 \%$ for the unemployed v. $30 \%$ for the partly retired) along with receiving benefits from Social Security or from an employer-provided plan.

\subsubsection{Transition to retirement}

At some point, individuals still not retired may make their transition toward retirement, meaning cessation of work for workers (whether they be part-time workers, full-time workers, or partly retired individuals), and abandoning the job search for the others (the unemployed as well as those partly retired individuals still looking for a job).

Full-time and part-time workers have quite similar retirement patterns by age: their retirement rate goes from roughly zero at age 55 to over 20 per cent at age 60 (meaning retirement between 
Figure 2: Retirement propensities by age and labor force status

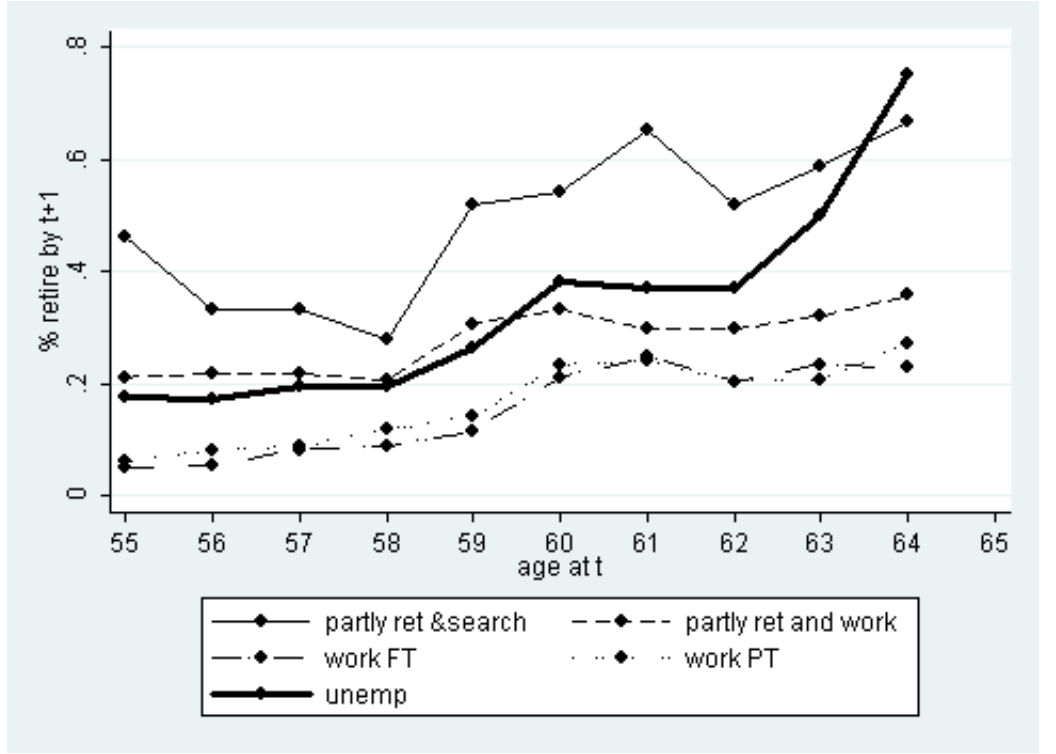

60 and 62), then keeps on rising until age 64 (between 64 and 66). The remaining part-time workers, who are part of the partly-retired group, have high retirement propensities at every age, around $20 \%$ from age 55 to 58 and $30 \%$ from age 59 until the end, so that the gap with other part-time workers shrinks as individuals age. This is consistent with their lower self-estimated probability of continuing to work full-time after 62 or 65 , which may be due to a lesser attachment to work or a greater preference for leisure. Therefore these individuals would be more likely to retire than their fellow part-time workers.

The unemployed workers are more prone to retire than full-time and part-time workers, and the gap between their retirement rates widens from age 60 . But they are less likely to retire than the partly retired who are looking for a job. Again, it seems that partly retired people share some individual features, which may explain their higher retirement propensity. As for the partly retired who are looking for a job, their retirement curve is unambiguously above every other one at every age. Indeed, these individuals are not working and already call themselves retirees, so the only criterion that differentiates them from the retired is the fact that they have not given up on the job search.

\subsection{Econometric analysis}

According to descriptive statistics, those "searchers" are more likely to retire than workers. But we need ceteris paribus analysis in order to disentangle the impact of looking for a job from that of other variables that are most likely to be highly correlated with the labor market status.

We study the impact of searching at some wave on the probability of retiring by the next wave 
by estimating probit equations. We control for socio-economic variables such as gender, marital status, household size, education, age (with quadratics), health, private and public pensions, total household wealth (with quadratics too), job-specific variables (tenure, self-employment, job history, earnings ${ }^{3}$ ), and wave and geographical dummies (see Table 5 in Appendix B). These control variables aim at limiting the importance of the selection effect for being unemployed versus employed.

The descriptive statistics allowed us to check that the partly retired individuals and their working or unemployed counterparts are quite similar regarding most characteristics. For this reason, partly retired individuals are split into two groups according to whether they work or search, and associated with the part-time workers or the unemployed accordingly. As can be seen in Table 4, looking for a job (compared to working) increases the probability of retiring by $19.5 \%$ (see Column (1) of Table 4).

But it could be a biased estimator of the impact of searching on the probability of retiring. Individuals who search may be partly retired or just unemployed, and workers may be full-time workers, part-time workers, or partly retired workers. The higher probability of retirement for the first group may capture the different behavior of partly-retired individuals. For instance, the high coefficient on "search" in Column (1) could be mainly driven by the partly retired.

We therefore study the impact of being in one of these four categories on the probability of retiring (Column (2)) because we suspect retirement patterns to differ between partly retired and others individuals. Indeed the searching partly retired are $37.5 \%$ more likely to retire than full-time workers, which drove upward the impact of job search on retirement in the preliminary regression (column (1)). On the other hand, the retirement probability of the working partly retired is $13 \%$ higher than that of full-time workers (whereas that of part-time workers is only slightly higher), which, acting as a compensating effect, drove upward the impact of working, and thus downward that of searching in Column (1).

In order to better identify the specificity of partly-retired people, and then the role of searching v. working, we now include the self-estimated probability of continuing work full-time after 62 or 65 (depending on the age of the individual) in the set of regressors ${ }^{4}$ (Column (3)). This latter variable could reveal different tastes for leisure or attachment to work. When controlled for that probability, the working partly retired become much more similar to the part-time workers (their probability of retiring is barely superior to that of full-time workers). Likewise, the marginal effect of the searching partly retired decreases from $37 \%$ to $23 \%$, which makes their retirement pattern much closer to that of the unemployed whose probability of retiring is $18 \%$ more than that of full-time workers. Let us note that this latter probability for the unemployed

\footnotetext{
${ }^{3}$ Earnings relate to the last calendar year so that non-working individuals may have positive earnings.

${ }^{4}$ Note that we have already controlled for receiving pension income in all regressions. But including them does not change the magnitude and significance of the marginal effects.
} 
Table 4: Probit regressions - Dependent variable: retire by next wave

\begin{tabular}{|c|c|c|c|c|}
\hline & $(1)$ & $(2)$ & (3) & (4) \\
\hline \multirow[t]{2}{*}{ searching } & $0.195^{* * *}$ & & & $0.188^{* * *}$ \\
\hline & $(10.26)$ & & & $(7.59)$ \\
\hline \multirow[t]{2}{*}{ working part-time } & & $0.0240^{* *}$ & -0.00567 & \\
\hline & & $(3.07)$ & $(-0.81)$ & \\
\hline \multirow[t]{2}{*}{ unemployed } & & $0.184^{* * *}$ & $0.181^{* * *}$ & \\
\hline & & $(8.05)$ & $(5.77)$ & \\
\hline \multirow[t]{2}{*}{ partly retired and searching } & & $0.375^{* * *}$ & $0.238^{* * *}$ & \\
\hline & & $(10.19)$ & $(5.72)$ & \\
\hline \multirow[t]{2}{*}{ partly retired and working } & & $0.127^{* * *}$ & $0.0438^{* * *}$ & \\
\hline & & $(11.47)$ & $(4.70)$ & \\
\hline \multirow[t]{2}{*}{ prob. continuing to work } & & & $-0.00154^{* * *}$ & $-0.00164^{* * *}$ \\
\hline & & & $(-25.33)$ & $(-28.17)$ \\
\hline Observations & 22,578 & 22,578 & 21,337 & 21,337 \\
\hline
\end{tabular}

Marginal effects; $t$ statistics in parentheses

Omitted category: works in column (1) and (4), works full-time in column (2) and (3).

for discrete change of dummy variable from 0 to 1

${ }^{*} p<0.05,{ }^{* *} p<0.01,{ }^{* * *} p<0.001$

is almost unchanged, meaning that the unemployed and employed workers share the same desire to participate in the labor market.

Once these unobserved preferences are taken into account, searching workers display the same probability of retiring, whatever they claim to be partially retired or unemployed, and the same statement applies for working people. "searching v. working" is indeed a discriminating piece of information explaining different retirement probabilities: the partly retired who search and the unemployed retire significantly more than full-time workers.

Once the self-estimated probability of continuing to work is taken into account, ${ }^{5}$ it is possible to capture the overall influence of searching v. working on the probability of retiring by splitting partly retired individuals into two groups according to whether they work or search. It appears that looking for a job (compared to working) increases the probability of retiring by $18.8 \%$ (Column (4)).

\footnotetext{
${ }^{5}$ Omitting this information could have led to bias in the estimates, but let us note that the biases introduced by the searching partly retired on the one hand and the working partly retired on the other hand almost compensate for each other, as the marginal effect of the search variable is actually remarkably stable between columns (1) and (4).
} 


\section{A canonical matching model with age-heterogeneity and en- dogenous retirement}

In this section, we propose a theoretical framework allowing us to explain simultaneously equilibrium unemployment and retirement. We extend the canonical matching model (Pissarides [1990]) to age heterogeneity and endogenous retirement decisions.

\subsection{Environment}

Time is continuous. Worker are finitely lived and are indexed by their age, denoted by $a$. At the age $a=T$, a worker dies and is replaced by a worker of age $a=0$. The labor market is populated by a continuum of agents of measure $T$, each cohort being of measure one. There are three possible occupations in the economy: employed, unemployed and retired. Any worker chooses her optimal occupation with respect to her opportunities. Unemployment and retirement occupations allow workers to produce at home the same amount of goods denoted by $b$, contrary to the employment occupation. For the moment, there is no social security and no unemployment insurance in our economy. Unemployment and employment occupations inflict the same disutility of market participation, $z(a)$, either the disutility of working or the disutility of searching, contrary to the retirement occupation. We assume that this participation cost is an increasing convex function, which reflects the wearing effect of aging on the labor market. This disutility is normalized at the beginning of the life-cycle such that $z(0)=0$ in order to ensure at least the participation of the youngest workers. As the disutility of participating in the labor market increases with age, retirement is expected to occur at some age. Let us denote $A_{e}$ and $A_{u}$ the retirement age of employed workers and of the unemployed workers respectively.

Following the canonical matching framework (Pissarides (2000)), we assume that the labor market is populated by a continuum of firms. Each firm produces with a constant return to scale technology that turns a unit of labor into $y$ units of output. Labor output is constant and homogenous among jobs. As usual, we assume that the private sector is more productive than the home sector, i.e. $y>b$.

We assume that the labor market is perfectly segmented by age. This assumption implies that if a vacancy directed to an age- $a$ worker meets a worker of age $a^{\prime} \neq a$, this match is unproductive ${ }^{6}$. Consistently with this directed-search assumption, there is one matching process by age denoted $M(v(a), u(a))$ where $u(a)$ and $v(a)$ are the respective number of age- $a$ unemployed workers and

\footnotetext{
${ }^{6}$ We assume that age- $a$ workers are not endowed with the required characteristics to become productive in an age- $a^{\prime}$ position. More precisely, let's denote $q\left(a^{\prime}\right)$ the age- $a^{\prime}$ worker ability and $p\left(a^{\prime}\right)$ the characteristic of a job requiring the age- $a^{\prime}$ ability. Following Mortensen and Pissarides [1999], we assume that $y>0$ if the match leads to the couple $\left(q\left(a^{\prime}\right), p\left(a^{\prime}\right)\right)$, whereas $y=0$ if the match leads to a couple $\left(q\left(a^{\prime}\right), p(a)\right), \forall a \neq a^{\prime}$. Under this assumption, the decentralized allocation with directed search is a stable equilibrium.
} 
of vacancies directed to this age. This assumption allows us to focus on the asymmetry between retirement ages of unemployed and employed workers, leaving aside the inefficiencies brought about by the age heterogeneity in an undirected search process. ${ }^{7}$ On the other hand, there is no on-the-job search. The matching function $M$ is such that $M_{1}>0, M_{2}>0, M_{1,1}<0$ and $M_{2,2}<0$. The Poisson rate at which a vacancy (unemployed worker) meets a unemployed worker (vacancy) is then defined as follows:

$$
\begin{aligned}
& \frac{M(v(a), u(a))}{v(a)}=q(\theta(a)) \text { with } q^{\prime}(\theta(a))<0 \\
& \frac{M(v(a), u(a))}{u(a)}=p(\theta(a)) \text { with } p^{\prime}(\theta(a))>0
\end{aligned}
$$

where $\theta(a) \equiv \frac{v(a)}{u(a)}$ is the labor market tightness of the age- $a$ sub-market. At each time, some matches are dissolved at the exogenous rate $s$.

Finally, wages are assumed to be the outcome of a Nash bargaining process. Wages are then also age-dependent and denoted by $w(a)$.

\subsection{Intertemporal values}

\subsubsection{Workers}

The value functions of the employed $(e)$, unemployed $(u)$ and retired $(r)$ workers are respectively given by:

$$
\begin{aligned}
r W_{e}(a) & =w(a)-z(a)+s\left[W_{g}(a)-W_{e}(a)\right]+\dot{W}_{e}(a) \\
r W_{u}(a) & =b-z(a)+p(\theta(a))\left[W_{e}(a)-W_{g}(a)\right]+\dot{W}_{g}(a) \\
r W_{r}(a) & =b+\dot{W}_{g}(a)
\end{aligned}
$$

For $a \in\left[0, A_{e}\right]$, the employed workers receive a flow of income $w(a)-z(a)$, the wage net of the disutility of working. At the rate $s$, they can lose their job, and then choose between unemployment and retirement: $W_{g}(a)=\max \left[W_{u}(a) ; W_{r}(a)\right]$. Employed workers choose to be retired at age $A_{e}$, and then get the intertemporal value $W_{r}\left(A_{e}\right)$.

For the unemployed workers, the flow of output $b-z(a)$ is the home production net of the cost of searching on the labor market. At the rate $p(\theta(a))$, the unemployed workers of age $a$ become employed. They choose to become retired at the age $A_{u}$, and then obtain the intertemporal value $W_{r}\left(A_{u}\right)$. It is then straightforward to see that unemployed workers will never search after the age $A_{e}$; should they find a job, they would quit immediately for retirement. They then choose retirement as unemployed in order to benefit immediately from the home production without paying the search cost. We have necessarily $A_{e} \geq A_{u}$.

\footnotetext{
${ }^{7}$ See Cheron, Hairault and Langot (2011) for a more comprehensive discussion on this point.
} 


\subsubsection{Firms}

The asset values associated with a job occupied by an age- $a$ worker and with a vacancy directed to the age- $a$ sub-market are respectively given by:

$$
\begin{aligned}
r J(a) & =y-w(a)+s[V(a)-J(a)]+\dot{J}(a) \text { for } a \leq A_{e} \\
r V(a) & =-c+q(\theta(a))[J(a)-V(a)] \text { for } a \leq A_{u}
\end{aligned}
$$

The free-entry condition implies that firms open vacancies until all rents are exhausted, i.e. $V(a)=0$. The labor market tightness at age $a$ then satisfies:

$$
\frac{c}{q(\theta(a))}=J(a)
$$

This free-entry condition and the integration of $J(a)$ then imply that:

$$
J(a)=\int_{a}^{A_{e}} e^{-(r+s)(\tau-a)}[y-w(\tau)] d \tau
$$

\subsection{Job surplus and wage bargaining over the life cycle}

Since search and hiring activities are costly, a joint surplus $S(a)$ is generated when a match is formed. The surplus is given by:

$$
S(a)=J(a)+W_{e}(a)-W_{g}(a)
$$

Firms and employees negotiate wages through a Nash bargaining process, where $\gamma$ is the worker's share of the surplus. The sharing rule then leads to:

$$
J(a)=(1-\gamma) S(a) \quad \text { and } \quad W_{e}(a)-W_{g}(a)=\gamma S(a)
$$

The best outside option for workers change over the life-cycle. Until $A_{u}$, the unemployment value dominates the retirement value $\left(W_{g}(a)=W_{u}(a)\right)$, whereas the opposite $\left(W_{g}(a)=W_{r}(a)\right)$ is true for $a>A_{u}$. It is possible to characterize these two regimes. Taking into account equations (1) and (4), it leads to:

$$
(r+s)\left[S(a)+W_{g}(a)\right]=y-z(a)+s W_{g}(a)+\dot{J}(a, \varepsilon)+\dot{W}_{e}(a)
$$

and

$$
(r+s) S(a)=y-z(a)-r W_{g}(a)+\dot{W}_{g}(a)+\dot{S}(a)
$$

From equations (2) and (3), we get:

$$
r W_{g}(a)-\dot{W}_{g}(a)=\left\{\begin{array}{lll}
b-z(a)+p(\theta(a)) \gamma S(a) & \text { if } \quad a \leq A_{u} \\
b & \text { if } \quad A_{u} \leq a \leq A_{e}
\end{array}\right.
$$


The job surplus expression in the two different regimes can then be deduced:

$$
(r+s) S(a)-\dot{S}(a)=\left\{\begin{array}{lll}
y-b-\gamma p(\theta(a)) S(a) & \text { if } & a \leq A_{u} \\
y-b-z(a) & \text { if } & A_{u} \leq a \leq A_{e}
\end{array}\right.
$$

Let us define $\psi(a)=y-b-\gamma p(\theta(a)) S(a)$ and $\phi(a)=y-b-z(a)$, the dynamics of the surplus are then given by:

$$
(r+s) S(a)-\dot{S}(a)=\chi(a), \text { with } \chi(a)=\min [\psi(a), \phi(a)]
$$

The integration of this equation leads to:

$$
S(a)=C e^{(r+s) a}-\int_{0}^{a} \chi(\tau) e^{-(r+s)(\tau-a)} d \tau
$$

At the retirement age $A_{e}$ of an employee, we have $S\left(A_{e}\right)=0$, implying that $C=\int_{0}^{A_{e}} \chi(\tau) e^{-(r+s) \tau} d \tau$. Finally, using equation (6), the sharing rules of the wage bargaining and $A_{u} \leq A_{e}$, the surplus can be rewritten as follows:

$S(a)= \begin{cases}\int_{a}^{A_{u}}\left[y-b-\frac{\gamma}{1-\gamma} c \theta(\tau)\right] e^{-(r+s)(\tau-a)} d \tau+\int_{A_{u}}^{A_{e}}[y-b-z(\tau)] e^{-(r+s)(\tau-a)} d \tau & \text { for } \quad a \leq A_{u} \\ \int_{a}^{A_{e}}[y-b-z(\tau)] e^{-(r+s)(\tau-a)} d \tau & \text { for } \quad A_{u} \leq a \leq A_{e}\end{cases}$

During the first stage of the life-cycle $\left(a \in\left[0 ; A_{u}\right]\right)$, the threat point of the employed worker is the unemployment occupation, leading the instantaneous surplus to be a function of the bargaining power $(\gamma)$ and of the labor tightness $(\theta(a))$, but independent of the participation disutility $(z(a))$ shared by the employed and the unemployed workers. In the last part of her life cycle $\left.\left.(a \in] A_{u} ; A_{e}\right]\right)$, the threat point becomes the retirement occupation, making the instantaneous surplus dependent on the participation disutility only.

\subsection{The retirement decisions}

The employed workers. Given that the wage bargaining process implies $W_{e}(a)-W_{g}(a)=$ $\gamma S(a)$, the decision rule concerning the retirement age of employed workers can be deduced from:

$$
\begin{aligned}
r W_{e}(a) & =w(a)-z(a)-s \gamma S(a)+\dot{W}_{e}(a) \\
\Rightarrow W_{e}(a) & =\max _{A_{e}} \int_{a}^{A_{e}} e^{-r(\tau-a)}[w(\tau)-z(\tau)-s \gamma S(\tau)] d \tau+e^{-r\left(A_{e}-a\right)} W_{r}\left(A_{e}\right)
\end{aligned}
$$

The first order condition with respect to $A_{e}$ is:

$$
b=w\left(A_{e}\right)-z\left(A_{e}\right)
$$

because $S\left(A_{e}\right)=0$. From the wage equation $w\left(A_{e}\right)=\gamma y+(1-\gamma)\left(b+z\left(A_{e}\right)\right)$, we deduce that the equilibrium retirement age of the employed workers is given by

$$
z\left(A_{e}\right)=y-b
$$


This rule simply says that employed workers participate as long as the marginal gain of working net of disutility $\left(y-z\left(A_{e}\right)\right)$ is greater than the marginal gain of inactivity $(b) .{ }^{8}$ These older workers cannot extract the rent arising from the saving of recruiting costs. This is why the retirement decision for employed workers is independent of the matching frictions, and only determined by the marginal employment surplus relative to the retirement opportunity.

The unemployed workers. For the unemployed workers, given that the wage bargaining process implies that $W_{e}(a)-W_{u}(a)=\gamma S(a)$, the decision rule concerning the optimal retirement age is deduced from:

$$
\begin{aligned}
r W_{u}(a) & =b-z(a)+p(\theta(a)) \gamma S(a)+\dot{W}_{u}(a) \\
\Rightarrow W_{u}(a) & =\max _{A_{u}} \int_{a}^{A_{u}} e^{-r(\tau-a)}[b-z(\tau)+p(\theta(\tau)) \gamma S(\tau)] d \tau+e^{-r\left(A_{u}-a\right)} W_{r}\left(A_{u}\right)
\end{aligned}
$$

The first order condition with respect to $A_{u}$ leads to: ${ }^{9}$

$$
b-z\left(A_{u}\right)+\gamma p\left(\theta\left(A_{u}\right)\right) S\left(A_{u}\right)=b
$$

The unemployed workers choose to participate as long as that the marginal gain of search activities $\left(b-z\left(A_{u}\right)+\gamma p\left(\theta\left(A_{u}\right)\right) S\left(A_{u}\right)\right)$ is greater than the marginal gain from inactivity $(b)$. Given the free entry condition (6) and the bargaining sharing rules, the first order condition can be rewritten as follows:

$$
\frac{\gamma}{1-\gamma} c \theta\left(A_{u}\right)=z\left(A_{u}\right)
$$

This condition emphasizes that $A_{u}$ is a function of the labor market tightness $\theta\left(A_{u}\right)$, as the latter determines the expected employment value: when the labor market provides high opportunities of contact $(\theta(a)$ high), the unemployed workers choose to delay their retirement age. Let us emphasize that the retirement age of employed workers influences that of unemployed workers through the labor market tightness. Indeed, equations (6) and (7) show that the vacancy investments on the age- $a$ segment of the labor market are a function of the retirement age of the employed workers, which determines the horizon of a new job: $\theta\left(A_{u}\right)$ is a function of $A_{e}$. A short horizon makes search costs difficult to recoup when the retirement age of the employed workers is imminent.

\subsection{The labor market flows by age}

Let us assume that the size of each generation is constant and normalized to unity. $u(a)$ denotes the rate of age- $a$ unemployed workers and $l(a)$ the rate of age- $a$ employed people:

$$
u(a)+l(a)=1
$$

\footnotetext{
${ }^{8}$ The second order condition of the problem is simply $-z^{\prime}\left(A_{e}\right)<0$. This condition is always satisfied given our assumption on $z(\cdot)$.

${ }^{9}$ The second order condition is $-z^{\prime}\left(A_{u}\right)<0$, which is satisfied due to the convexity of the function $z$.
} 
At steady state, the age dynamics of the unemployment rate, for $a \leq A_{u}$, are given by:

$$
\dot{u}(a)=s(1-u(a))-p(\theta(a)) u(a), a \leq A_{u}
$$

Assuming that the initial condition is $u(0)=1$, the unemployment rate by age, using (11), equals:

$$
u(a)=e^{-\int_{0}^{a}[s+p(\theta(\tau))] d \tau}\left\{1+s \int_{0}^{a} e^{\int_{0}^{\xi}[s+p(\theta(x))] d x} d \xi\right\}, a \leq A_{u}
$$

On the other hand, when unemployed workers choose to be retired $\left(a>A_{u}\right)$, implying that $\dot{l}(a)=-s l(a)$, the employment rate of age $a$ is given by:

$$
l(a)=\left[1-u\left(A_{u}\right)\right] e^{-\int_{A_{u}}^{a} s d \tau}=\left[1-u\left(A_{u}\right)\right] e^{-s\left(a-A_{u}\right)}, \quad A_{u} \leq a \leq A_{e}
$$

\subsection{The labor market equilibrium}

Definition 1. Assuming a free-entry condition, leading to the zero-profit condition $V(a)=0$, $\forall a$, the labor market equilibrium with directed search in a finite-horizon environment is defined by:

$$
\begin{aligned}
S(a) & =\left\{\begin{array}{l}
\int_{a}^{A_{u}} e^{-(r+s)(\tau-a)}\left[y-b-\frac{\gamma}{1-\gamma} c \theta(\tau)\right] d \tau+\int_{A_{u}}^{A_{e}} e^{-(r+s)(\tau-a)}[y-b-z(\tau)] d \tau \text { for } a \leq A_{u} \\
\int_{a}^{A_{e}}[y-b-z(\tau)] e^{-(r+s)(\tau-a)} d \tau \text { for } A_{u} \leq a \leq A_{e}
\end{array}\right. \\
\frac{c}{q(\theta(a))} & =(1-\gamma) S(a) \text { for } a \leq A_{u} \\
z\left(A_{e}\right) & =y-b \\
z\left(A_{u}\right) & =\frac{\gamma}{1-\gamma} c \theta\left(A_{u}\right) \\
u(a) & =e^{-\int_{0}^{a}[s+p(\theta(\tau))] d \tau}\left\{1+s \int_{0}^{a} e^{\int_{0}^{x}[s+p(\theta(\tau))] d \tau} d x\right\} \quad \forall a \leq A_{u} \\
l(a) & =\left[1-u\left(A_{u}\right)\right] e^{-s\left(a-A_{u}\right) \quad \forall a \leq A_{u}} \quad \forall \quad
\end{aligned}
$$

with $u=\frac{1}{A_{u}} \int_{0}^{A_{u}} u(\tau) d \tau$. The initial condition is given by $u(0)$.

The labor market equilibrium is block-recursive. Given the retirement age of the employed workers (equation (15)), by backward iteration, we successively derive the values for $S(a), \forall a \in$ ]$A_{u}, A_{e}$ ] (equation (13)). It is also possible to compute the expected surplus of hiring an age- $A_{u}$ worker (the oldest hired worker). The values of $A_{u}$ and $\theta\left(A_{u}\right)$ are then simultaneously determined by the job creation condition (equation (14)) and the participation decision (equation (16)). For these values of the jump variables, it is then possible to compute the stocks of unemployed and employed workers (equations (17) and (18)).

From the conditions characterizing the unemployment and retirement decisions, it is possible to study the properties of the retirement age conditionally on the labor market status. 
Proposition 1. If $z(T)>y-b$ and $z^{\prime}>0$, then there exists a unique pair $\left\{A_{e}, A_{u}\right\}$, with $A_{e}>A_{u}$.

Proof. It is first necessary that $A_{e} \leq T$, otherwise workers would work until death: this restriction implies that $y-b \leq z(T)$. Secondly, assuming that $A_{e}>A_{u}$, the optimal retirement age $A_{u}$ and the labor market tightness $\theta\left(A_{u}\right)$ are determined by the following system:

$$
\begin{aligned}
(J C) & \frac{c}{q\left(\theta\left(A_{u}\right)\right)} & =(1-\gamma) \int_{A_{u}}^{A_{e}}[y-b-z(\tau)] e^{(r+q)\left(A_{u}-\tau\right)} d \tau \\
(R A) & b & =b-z\left(A_{u}\right)+\frac{\gamma}{1-\gamma} c \theta\left(A_{u}\right)
\end{aligned}
$$

The job creation curve $(J C)$ is negatively sloped in the space $\left(A_{u}, \theta\left(A_{u}\right)\right)$ whereas the retirement age curve $(R A)$ is positively sloped. Moreover, the assumption $z(0)=0$ ensures that $(R A)$ crosses the origin, whereas $(J C)$ takes a strictly positive value at the origin. Thus, this determines a unique intersection point $\left(A_{u}, \theta\left(A_{u}\right)\right)$ that stands for the equilibrium retirement age $A_{u}$.

It is worth emphasizing that the productivity measure $y$ has a differentiated impact on the retirement ages $A_{e}$ and $A_{u}$ : the retirement age of employed workers $A_{e}$ depends directly on $y$, and not $A_{u}$.

Proposition 2. A permanent increase in the productivity raises less $A_{e}$ than $A_{u}$.

Proof. Let us assume for simplicity that $z(a)=\bar{z} e^{\mu a}$ and $\frac{-q^{\prime}(\theta) \theta}{q(\theta)}=1-\eta$. The changes in the equilibrium values following a permanent increase $d y>0, \forall a \geq A_{u}$ :

$$
\begin{aligned}
\mu d A_{e} & =\frac{y}{y-b} \frac{d y}{y} \\
\mu d A_{u} & =\frac{d \theta\left(A_{u}\right)}{\theta\left(A_{u}\right)} \\
(1-\eta) \frac{d \theta\left(A_{u}\right)}{\theta\left(A_{u}\right)} & =\frac{d S\left(A_{u}\right)}{S\left(A_{u}\right)} \\
\frac{d S\left(A_{u}\right)}{S\left(A_{u}\right)} & =\frac{y \int_{A_{u}}^{A_{e}} e^{-(r+s)\left(\tau-A_{u}\right)} d \tau}{\int_{A_{u}}^{A_{e}} e^{-(r+s)\left(\tau-A_{u}\right)}(y-b-z(\tau)) d \tau} \frac{d y}{y}
\end{aligned}
$$

The variations in the retirement age of the unemployed workers on the one hand and of the employed workers on the other hand are then summarized by:

$$
\begin{aligned}
\mu d A_{e} & =\frac{y}{y-b} \frac{d y}{y} \\
\mu d A_{u} & =\frac{1}{1-\eta} \frac{y \int_{A_{u}}^{A_{e}} e^{-(r+s)\left(\tau-A_{u}\right)} d \tau}{\int_{A_{u}}^{A_{e}} e^{-(r+s)\left(\tau-A_{u}\right)}(y-b-z(\tau)) d \tau} \frac{d y}{y}
\end{aligned}
$$

As we have $\frac{y}{y-b}<\frac{y}{y-b-\underline{z}}<\frac{y I}{(y-b) I-\int_{A_{u}}^{A_{e}} e^{-(r+s)\left(\tau-A_{u}\right)} z(\tau) d \tau}$ with $I=\int_{A_{u}}^{A_{e}} e^{-(r+s)\left(\tau-A_{u}\right)} d \tau$ and $z(\cdot)^{\prime}>0$ on $\left[\underline{z} ; \infty\left[\right.\right.$ then necessarily $d A_{u}>d A_{e}$. 
Proposition 2 shows that a rise in productivity leads to increasing more the retirement age of the unemployed workers than that of the employed workers, leading to a reduction in the gap between the retirement ages. This result comes from two channels. First, whereas $d y>0$ has a linear impact on the expected job surplus, the free entry condition is satisfied for a more than proportional variation in the labor market tightness. This effect is captured by the term $\frac{1}{1-\eta}>1$. Secondly, the retirement age decision of unemployed workers depends on the labor market tightness and so on the expected surplus over all ages $a \in\left[A_{u}, A_{e}\right]$. Beyond the effect on the marginal age as for the employed workers, there is a positive surplus at each age $a \in\left[A_{u}, A_{e}\right]$. Extrapolating this result a little, it is possible to conclude that business cycles can affect the retirement age gap between employed and unemployed workers. Recessions would then make the average retirement age lower through three different channels: first, as expected, all workers choose to retire sooner. Secondly, there are more unemployed people for a given retirement gap; finally, the retirement gap is larger in recession. This gives some theoretical grounds to the recent empirical evidence shown by Coile and Levine (2012) that the recent recession with the subsequent huge increase in unemployment has led to a decline in the average retirement.

\section{7 $\quad$ First best allocation}

The previous section highlighted economic rationales sustaining age heterogeneity in the retirement decision across employed and unemployed people. It remains to study whether this behavior is consistent with social optimality.

The problem of the planner is to determine the optimal allocation of each worker between the production and the search sectors at each age, by choosing the optimal investment in the search sector and the optimal retirement ages. The per-unemployed worker social value in the search sector and the per-employed worker social value in the production sector are respectively given by:

$$
\begin{aligned}
Y_{u}(a)= & \max _{\left\{A_{u}, \theta(\tau), A_{e}\right\}} \int_{a}^{A_{u}} e^{-r(\tau-a)}[b-z(\tau)-c \theta(\tau)+p(\theta(\tau)) Y(\tau)] d \tau \\
& +e^{-r\left(A_{u}-a\right)} Y_{r}\left(A_{u}\right)
\end{aligned}
$$

subject to the constraints:

$$
\begin{aligned}
Y(a) & =Y_{e}(a)-\max \left\{Y_{u}(a), Y_{r}(a)\right\} \\
Y_{e}(a) & =\int_{a}^{A_{e}} e^{-(r+s)(\tau-a)}\left[y-z(\tau)+s \max \left\{Y_{u}(\tau), Y_{r}(\tau)\right\}\right] d \tau+e^{-(r+s)\left(A_{e}-a\right)} Y_{r}\left(A_{e}\right) \\
Y_{r}(a) & =\int_{a}^{T} e^{-r(\tau-a)} b d \tau
\end{aligned}
$$

$b-z(a)$ represents the instantaneous home production net of the disutility of searching and $c \theta(a)$ is the instantaneous cost of a vacancy per unemployed worker. The first order conditions of the 
planner are:

$$
\begin{aligned}
b & =b-z\left(A_{u}\right)-c \theta\left(A_{u}\right)+p\left(\theta\left(A_{u}\right)\right) Y\left(A_{u}\right) \\
c & =p^{\prime}(\theta(a)) Y(a) \\
b & =y-z\left(A_{e}\right)
\end{aligned}
$$

Given that $\eta=1-\frac{\theta p^{\prime}(\theta(a))}{p(\theta(a))}$ and $p(\theta(a))=\theta(a) q(\theta(a))$, these first order conditions can be rewritten as follows:

$$
\begin{aligned}
z\left(A_{e}\right) & =y-b \\
z\left(A_{u}\right) & =\frac{\eta}{1-\eta} c \theta\left(A_{u}\right) \\
\frac{c}{q(\theta(a))} & =(1-\eta) Y(a)
\end{aligned}
$$

Proposition 3. The equilibrium allocation does not coincide with the first best allocation, except when the Hosios condition $\gamma=\eta$ is satisfied.

Proof. By comparing equilibrium and optimum conditions, it is straightforward that the condition $\gamma=\eta$ is necessary to make them coincide.

The search externalities conveyed by the matching model make the retirement age of unemployed workers not optimal, whereas the retirement decision of employed workers is free of the inefficiencies generated by the uncoordinated matching process, as the best outside opportunity is retirement. How far the labor market is from the Hosios condition determines how far the retirement age of unemployed people is from optimality. Retirement of unemployed individuals can happen either too soon or too late, for a given retirement age of employed workers, depending on the number of vacancies that are created by firms at the equilibrium. Let us emphasize that the optimality of the retirement age of unemployed workers is defined relative to the retirement age of employed workers. Should the latter be suboptimal, the Hosios condition would still ensure the optimality of the retirement age of unemployed workers.

As the optimality of the unemployed workers retirement goes through that of the labor market tightness, any labor-market institutions influencing the job finding probability affect the unemployment retirement age and determine its degree of optimality. In that sense, if the analysis of retirement can be reduced to labor supply decisions for employed workers, only a general equilibrium approach can highlight the key dimensions of the retirement of unemployed workers.

\subsection{Policy issues}

Welfare and policy analysis of retirement decisions must take into account the labor-market status and adopt a clear distinction between the employed and the unemployed workers. In this 
section, we analyze the optimal properties of the Social Security system according to the labor market status.

In the previous sections, there was no Social Security system. Hereafter, let us consider the existence of Social Security (SS) provisions at the market equilibrium financed by workers' contributions. We assume that the social security contributions are proportional to the worker's wage ${ }^{10}$ : the contribution rate $\tau_{w}$ is set to balance the SS budget. We also assume that the pension depends on the labor market occupation of the worker just before the retirement age, and is an increasing function of the retirement age: the function $\pi_{s}(a)$, for $s=e, u$, gives the pension level at each age, and her dependence on age $a$ takes into account the pension adjustments due to delayed retirement. We do not introduce any additional distortions. In particular, the Hosios condition $\gamma=\eta$ is assumed to hold and so the retirement decisions would be optimal without the SS system.

It remains to deal with the two potential sources of distortions brought about by the SS system, the contribution rate and the implicit tax on continued activity. We consider the distortions brought by the tax rate as given and only discuss the optimal pension adjustments. In general, it is often argued that Social Security provisions should be actuarially neutral at the margin in order not to distort the retirement decision. Contributions collected during additional working years and the forgone pensions due to this delayed retirement should be exactly matched by an increase in the value of the pension received over a shorter retirement period: the implicit tax on continued activity imposed by the SS system should be removed by implementing actuarially fair pension adjustments. In this section, we will show that taking into account the labor market equilibrium with search frictions questions this conventional wisdom. The complete elimination of the implicit tax is not necessarily welfare-optimizing in a second best world where the labor market suffers from distortions. Hereafter, we will focus on the distortions brought about by the SS system, but this analysis could be extended to any distortions on job creations (bargaining power, unemployment benefits and so on).

\subsubsection{Retirement behaviors and Social Security}

Let us reconsider the retirement value of a worker according to her labor market status when retiring at age $A_{s}$ :

$$
\begin{aligned}
W_{s, r}\left(a, A_{s}\right) & =\int_{a}^{T} e^{-r(\tau-a)}\left[b+\pi_{s}\left(A_{s}\right)\right] d \tau=\frac{b+\pi_{s}\left(A_{s}\right)}{r}\left(1-e^{-r(T-a)}\right) \\
\Rightarrow r W_{s, r}\left(a, A_{s}\right) & =b+\pi_{s}(A)+\dot{W}_{s, r}\left(a, A_{s}\right)
\end{aligned}
$$

\footnotetext{
${ }^{10}$ In general, unemployed workers do not pay contributions to the SS system. This point is inessential for our argument.
} 
The retirement age $A_{e}$ for employed workers is the solution to the following problem:

$$
S(a)=\max _{A_{e}}\left[\int_{a}^{A_{e}} e^{-(r+s)(\tau-a)}\left[y-z(\tau)-\tau_{w} w(\tau)+s W_{e, r}(\tau, \tau)\right] d \tau+e^{-(r+s)\left(A_{e}-a\right)} W_{e, r}\left(A_{e}, A_{e}\right)-W_{e, r}(a, a)\right]
$$

The first order condition of this problem determines the individually-optimal retirement age for employed workers:

$$
z\left(A_{e}\right)+\mathcal{T}_{e}\left(A_{e}\right)=y-b
$$

where $\mathcal{T}_{e}\left(A_{e}\right)=\tau_{w} w\left(A_{e}\right)+\pi_{e}\left(A_{e}\right)-\frac{\pi_{e}^{\prime}\left(A_{e}\right)}{r}\left(1-e^{-r\left(T-A_{e}\right)}\right)$ is the implicit tax on the continuation of the activity. When $\mathcal{T}_{e}\left(A_{e}\right) \neq 0$, the SS system is not actuarially fair at the margin: contributions collected during additional working years and the forgone pensions due to this delayed retirement are not exactly matched by an increase in the value of the pension received over a shorter retirement period. Compared with the socially efficient rule given by equation (19), the gap between the individual and the optimal retirement ages comes only from the distortion due to the implicit tax $\mathcal{T}_{e}\left(A_{e}\right)$. This is why an actuarially-fair pension adjustment such that $\mathcal{T}_{e}\left(A_{e}\right)=0$ is socially optimal.

On the other hand, for the unemployed worker, the optimal retirement age is the solution to the following problem:

$$
W_{u}(a)=\max _{A_{u}} \int_{a}^{A_{u}} e^{-\int_{a}^{\tau}(r+p(\theta(x))) d x}\left[b-z(\tau)+p(\theta(\tau)) W_{e}(\tau)\right] d \tau+e^{-\left(r+p\left(\theta\left(A_{u}\right)\right)\right)\left(A_{u}-a\right)} W_{u, r}\left(A_{u}, A_{u}\right)
$$

The individually-optimal decision corresponds to the following first order condition:

$$
z\left(A_{u}\right)+\mathcal{T}_{u}\left(A_{u}\right)=p\left(\theta\left(A_{u}\right)\right)\left(W_{e}\left(A_{u}\right)-W_{u, r}\left(A_{u}, A_{u}\right)\right)
$$

where $\mathcal{T}_{u}\left(A_{u}\right)=\pi_{u}\left(A_{u}\right)-\frac{\pi_{u}^{\prime}\left(A_{u}\right)}{r}\left(1-e^{-r\left(T-A_{u}\right)}\right)$ the implicit taxation on continued activity for unemployed workers, which takes into account that unemployed workers do not contribute to the SS system. Using the solution of the Nash bargaining problem, leading to $J(a)=\frac{1-\eta}{1-\eta+\eta\left(1-\tau_{w}\right)} S(a)$ and $\left(W_{e}(a)-W_{e, r}(a, A)\right)=\frac{\eta\left(1-\tau_{w}\right)}{1-\eta+\eta\left(1-\tau_{w}\right)} S(a)$, we obtain

$$
z\left(A_{u}\right)+\mathcal{T}\left(A_{u}\right)=\frac{\eta\left(1-\tau_{w}\right)}{1-\eta} c \theta\left(A_{u}\right)
$$

The distortion created by the contribution rate $\tau_{w}$ implies a gap between the individual and the optimal retirement ages for the unemployed workers beyond the existence of the implicit tax $\mathcal{T}\left(A_{u}\right)$. How the job surplus is divided between workers and firms through the Nash bargaining directly matters for the retirement decision of the unemployed people. It is then obvious that an actuarially fair pension adjustment such that $\mathcal{T}_{u}\left(A_{u}\right)=0$ does not necessarily lead to an optimal decision. This is all the more true in that the labor market tightness $\theta\left(A_{u}\right)$ is also distorted by the contribution rate at the market equilibrium, which in turn also distorts the retirement decision of the unemployed. This is why an actuarially unfair SS system might compensate for these labor market distortions at the market equilibrium. 


\subsubsection{The labor market equilibrium with SS system}

Definition 2. Assuming a free-entry condition, leading to the zero-profit condition $V(a)=0$, $\forall a$, the directed search equilibrium with a SS system in a finite-horizon environment is defined by:

$$
\begin{aligned}
S(a) & = \begin{cases}\int_{a}^{A_{u}} e^{-(r+s)(\tau-a)}\left[y-b-\frac{\eta\left(1-\tau_{w}\right)}{1-\eta} c \theta(\tau)-\mathcal{T}_{e}(\tau)\right] d \tau \\
+\int_{A_{u}}^{A_{e}} e^{-(r+s)(\tau-a)}\left[y-b-z(\tau)-\mathcal{T}_{e}(\tau)\right] d \tau & \text { for } a \leq A_{u} \\
\int_{a}^{A_{e}}\left[y-b-z(\tau)-\mathcal{T}_{e}(\tau)\right] e^{-(r+s)(\tau-a)} d \tau & \text { for } A_{u} \leq a \leq A_{e}\end{cases} \\
\frac{c}{q(\theta(a))} & =\frac{1-\eta}{1-\eta+\eta\left(1-\tau_{w}\right)} S(a) \quad \text { for } a \leq A_{u} \\
z\left(A_{e}\right) & =y-b-\mathcal{T}_{e}\left(A_{e}\right) \\
z\left(A_{u}\right) & =\frac{\eta\left(1-\tau_{w}\right)}{1-\eta} c \theta\left(A_{u}\right)-\mathcal{T}_{u}\left(A_{u}\right)
\end{aligned}
$$

with (17) and (18) unchanged and $u=\frac{1}{A_{u}} \int_{0}^{A_{u}} u(\tau) d \tau$. The initial condition is given by $u(0)$.

Equation (22) shows that the individual job surplus is distorted by the individual evaluation of the search costs for $a \leq A_{u}$ and by the tax on the continuation on activity $\mathcal{T}(a), \forall a$. Equation (23) emphasizes that the sharing rule of the job surplus between workers and firms is not optimal due to the existence of the distortive $\operatorname{tax} \tau_{w}$. More precisely, the tax rate acts as an increase in the bargaining power of the firms $\left(\frac{1-\eta}{1-\eta+\eta\left(1-\tau_{w}\right)}>1-\eta\right)$, leading to a too high labor market tightness. The retirement age $A_{u}$, given by equation (25), is distorted in the same manner as the job surplus.

Proposition 4. The optimal pension adjustment for employed workers must be actuarially fair at age $A_{e}$ and must impose an overall implicit taxation on activity otherwise. The optimal pension adjustments for unemployed people must subsidize activity.

Proof. Using equations (21), (23), and the definitions for $S(a)$ and $Y(a)$, we deduce that $\theta(a)=$ $\theta^{\star}(a)$ if and only if:

$$
\begin{aligned}
& \int_{a}^{A_{u}^{\star}} e^{-(r+s)(\tau-a)} \mathcal{T}_{e}(\tau) d \tau=\eta \tau_{w} \int_{a}^{A_{u}^{\star}} e^{-(r+s)(\tau-a)}\left[y-b+c \theta^{\star}(\tau)\right] d \tau \quad \text { for } a \leq A_{u}^{\star} \\
& \int_{A_{u}^{\star}}^{A_{e}^{\star}} e^{-(r+s)(\tau-a)} \mathcal{T}_{e}(\tau) d \tau=\eta \tau_{w} \int_{A_{u}^{\star}}^{A_{e}^{\star}} e^{-(r+s)(\tau-a)}[y-b-z(\tau)] d \tau \quad \text { for } A_{u}^{\star}<a \leq A_{e}^{\star}
\end{aligned}
$$

The actualized sum of the implicit taxes $\mathcal{T}_{e}(a)$ must be positive because $y-b-z(a) \geq 0$, for $a>A_{u}^{\star}$ and $y-b+c \theta^{\star}(a)>0$, for $a \leq A_{u}^{\star}$. The terminal condition satisfies $\mathcal{T}_{e}\left(A_{e}^{\star}\right)=0$ implying that the retirement age for the employed worker is optimal (see equations (19) and (24)). From the equations (20) and (25), we deduce that the retirement age of the unemployed workers is optimal if and only if:

$$
\mathcal{T}_{u}(a)=-\tau_{w} \frac{\eta}{1-\eta} c \theta^{\star}(a)<0
$$


Subsidizing activity is optimal. Before $A_{u}^{\star}$, this policy ensures that $\left(1-\tau_{w}\right) \frac{\eta}{1-\eta} c \theta(a)>z(a)+$ $\mathcal{T}_{u}(a)$ which is similar to the condition $\frac{\eta}{1-\eta} c \theta(a)>z(a)$ in the planner's problem.

For the unemployed workers, before $A_{u}$ and at age $A_{u}$, the SS system must cope with the labor market distortions: for an optimal labor market tightness $\theta^{\star}(a)$, the unemployed worker must receive a subsidy, which compensates for the negative effect of the contribution rate on her effective bargaining power. The prospects associated with finding a job are too low due to the labor tax, activity must be subsidized: the pension adjustments must encourage unemployed people to delay their retirement.

Moreover, the expected implicit taxes associated with the pension adjustments for employed workers can help to restore the optimality of the labor market tightness $\theta_{a}$ by decreasing the job surplus foreseen at any age $a$. For the employed workers, the SS system must compensate for the too high bargaining power of firms which leads them to over-invest in vacancies: an implicit tax is then optimal in order to decrease the job surplus. Let us emphasize that the value of the implicit taxes $\mathcal{T}_{e}(a)$ is then modified at age $A_{u}$ when the value of the job surplus is changed by the modification in the outside option of the worker.

A particular solution for the sequence of $\mathcal{T}_{e}(a)$ is given by:

$$
\begin{aligned}
& \mathcal{T}_{e}(a)=\eta \tau_{w}\left[y-b+c \theta^{\star}(a)\right] \quad \text { for } a \leq A_{u}^{\star} \\
& \mathcal{T}_{e}(a)=\eta \tau_{w}[y-b-z(a)] \text { for } a>A_{u}^{\star}
\end{aligned}
$$

Given that $\mathcal{T}_{e}(a)=\tau_{w} w^{\star}(a)+\pi_{e}(a)-\frac{\pi_{e}^{\prime}(a)}{r}\left(1-e^{-r(T-a)}\right)$ and $w^{\star}(a)=\eta\left(y+c \theta^{\star}(a)\right)+(1-\eta) b$, for $a \leq A_{u}^{\star}$, and $w^{\star}(a)=\eta y+(1-\eta)[b+z(a)]$, for $a>A_{u}^{\star}$, the value of the pension adjustments for employed workers consistent with the optimal taxation imposed by the SS system is the solution to:

$$
\begin{aligned}
& \tau_{w} b+\pi_{e}(a)=\frac{\pi_{e}^{\prime}(a)}{r}\left(1-e^{-r(T-a)}\right) \quad \text { for } a \leq A_{u}^{\star} \\
& \tau_{w}[b+z(a)]+\pi_{e}(a)=\frac{\pi_{e}^{\prime}(a)}{r}\left(1-e^{-r(T-a)}\right) \text { for } a>A_{u}^{\star}
\end{aligned}
$$

The actualized sum of the pension adjustments must compensate for all the forgone pension, but only for a fraction of the SS contributions: those proportional to the reservation wage, and not those effectively paid on wages. Note that the pension adjustment must be higher after age $A_{u}$, because the outside option (retirement) saves the worker from the disutility of participating in the labor market.

On the other hand, for the unemployed workers, the pension adjustments proposed by the SS system must be such that:

$$
\tau_{w} \frac{\eta}{1-\eta} c \theta^{\star}(a)+\pi_{u}(a)=\frac{\pi_{u}^{\prime}(a)}{r}\left(1-e^{-r(T-a)}\right)
$$


The pension adjustments lead to subsidizing activity because they should compensate for the search costs in addition to the forgone pensions.

Overall, due to search frictions, the marginal actuarial fairness is no longer a necessary condition to ensure the social optimality of retirement decision, except at the retirement age for the employed workers. The optimal pension adjustment for employed workers must impose an overall implicit taxation, whereas the optimal pension adjustments for unemployed people must subsidize activity.

\section{Conclusion}

This paper is a first contribution to understanding the respective retirement behavior of unemployed and employed workers. Consistently with previous empirical evidence (Coile and Levine (2006, 2012)), using the Health and Retirement Survey dataset, we show that the labor market status, more especially working v. searching for a job, is a very significant characteristic which explains the individual retirement decision: to be unemployed increases by $19 \%$ the probability of retiring relative to employed workers aged between 50 and 70 .

A canonical matching model with only age heterogeneity arising from an age-increasing disutility of participating in the labor market is enough to deliver an explanation for this result. The existence of search frictions makes the unemployment value inferior to the employment value at any age, and so the retirement value dominates the unemployment value sooner it does for the employment value. Besides this direct implication of the search frictions, this approach reveals that the retirement decision crucially differs according to the labor market status. First, the retirement decision of unemployed workers depends on the conditions which would prevail if those workers were employed. The search return when unemployed depends on the horizon until retirement once re-employed. In that sense, the retirement age of employed workers determines that of the unemployed. Moreover, the former is independent of the labor market tightness, contrary to the latter. This is why their optimality conditions greatly differ. The existence of search externalities makes the retirement age of unemployed workers sub-optimal, whereas the retirement decision of employed workers is free of the inefficiencies generated by the uncoordinated matching process, as the best outside opportunity is retirement. This deep asymmetry also explains why the retirement decisions of unemployed and employed workers react in a different way to shocks. It also changes the optimal pension adjustment schemes, which must move away from the marginal actuarial fairness.

Overall, this paper shows that unemployment and retirement deserve to be analyzed in an integrated framework. Retirement is one of the main participation decision over the life cycle, which has strong feedback effects on the labor market flows (Hairault, Langot and Sopraseuth (2010), Chéron, Hairault and Langot (2011)). On the other hand, the labor market status is one of the 
main factors guiding the retirement decision. Another natural extension will be to endogeneize health status and to analyze its interaction with labor market status and retirement. This is left for further research. 


\section{References}

[1] J. Albrecht, L. Navarro and S. Vroman, Efficiency in a search and matching model with endogenous participation, Economic Letters, 106 (2010), pp. 48-50.

[2] A. Chéron, J.O. Hairault and F. Langot, Age-Dependent Employment Protection, Economic Journal, 121(557), (2011) 1477-1504.

[3] C. Coile and P. Levine, Bulls, Bears, and Retirement Behavior. Industrial and Labor Relations Review, 59(3), (2006), 408-429.

[4] C. Coile and P. Levine, Labor Market Shocks and Retirement: Do Government Programs Matter? Journal of Public Economics, Forthcoming.

[5] E. French, The Effects of Health, Wealth, and Wages on Labor Supply and Retirement Behavior, Review of Economic Studies, 72(2) (2005), 395-427.

[6] P. Garibaldi and E. Wasmer, Equilibrium search unemployment, endogenous participation and labor market flows Journal of European Economic Association, 3(4), (2005) 441-463.

[7] A. Gustman and T. Steinmeier, The social security early entitlement age in a structural model of retirement and wealth, Journal of Public Economics, 89(2-3), (2005) 441-463.

[8] J-O. Hairault, F. Langot, and T. Sopraseuth, Distance to Retirement and Older Workers' Employment: The Case For Delaying The Retirement Age. Journal of European Economic Association, 85 (2010), pp. 1034-1076.

[9] A.J. Hosios, On the efficiency of matching and related models of search and unemployment, Review of Economic Studies 57 (1990), pp. 279-298.

[10] L. Ljungqvist and T. Sargent, Two Questions About European Unemployment, Econometrica, 76 (2008), 1-30.

[11] C. Pissarides, Equilibrium Unemployment Theory, Second edition, Cambridge, MA: MIT Press, (2000).

[12] J. Seater, A unified model of consumption, labor supply and job search, Journal of Economics Theory, 14 (1977), pp. 349-372.

\section{A Probit regressions}


Table 5: Probit regressions - Control variables

\begin{tabular}{|c|c|c|c|}
\hline & (1) & $(2)$ & (3) \\
\hline \multirow[t]{2}{*}{ male } & $-0.0132^{*}$ & $-0.0113^{*}$ & -0.00611 \\
\hline & $(-2.45)$ & $(-2.08)$ & $(-1.14)$ \\
\hline \multirow[t]{2}{*}{ marital status:in couple } & $0.0144^{*}$ & 0.00991 & 0.00218 \\
\hline & $(2.46)$ & $(1.68)$ & $(0.37)$ \\
\hline \multirow[t]{2}{*}{ education:high attainment } & $-0.0131^{* *}$ & $-0.0176^{* * *}$ & -0.00858 \\
\hline & $(-2.63)$ & $(-3.55)$ & $(-1.74)$ \\
\hline \multirow[t]{2}{*}{ age } & $0.182^{* * *}$ & $0.186^{* * *}$ & $0.279^{* * *}$ \\
\hline & $(3.75)$ & $(3.85)$ & $(5.80)$ \\
\hline \multirow[t]{2}{*}{$\operatorname{age}^{2}$} & $-0.00130^{* *}$ & $-0.00134^{* *}$ & $-0.00211^{* * *}$ \\
\hline & $(-3.16)$ & $(-3.28)$ & $(-5.18)$ \\
\hline \multirow[t]{2}{*}{ health:excellent } & $-0.0208^{* * *}$ & $-0.0202^{* * *}$ & $-0.0161^{* *}$ \\
\hline & $(-3.56)$ & $(-3.47)$ & $(-2.77)$ \\
\hline \multirow[t]{2}{*}{ health:fair or poor } & $0.0556^{* * *}$ & $0.0575^{* * *}$ & $0.0453^{* * *}$ \\
\hline & $(7.04)$ & $(7.27)$ & $(5.85)$ \\
\hline \multirow[t]{2}{*}{ health:problems limit work } & $0.0706^{* * *}$ & $0.0592^{* * *}$ & $0.0463^{* * *}$ \\
\hline & $(7.67)$ & $(6.62)$ & $(5.28)$ \\
\hline \multirow[t]{2}{*}{ no. of people in the household } & $-0.00632^{* *}$ & $-0.00511^{*}$ & -0.00315 \\
\hline & $(-3.03)$ & $(-2.47)$ & $(-1.54)$ \\
\hline \multirow[t]{2}{*}{ receives SS benefits } & 0.00119 & $-0.0297^{* *}$ & $-0.0370^{* * *}$ \\
\hline & $(0.11)$ & $(-3.19)$ & $(-4.34)$ \\
\hline \multirow[t]{2}{*}{ receives private pension } & $0.0420^{* * *}$ & 0.0128 & 0.00526 \\
\hline & $(5.13)$ & $(1.66)$ & $(0.71)$ \\
\hline \multirow[t]{2}{*}{ total household wealth (million\$) } & $0.154^{* * *}$ & $0.137^{* * *}$ & $0.0963^{* * *}$ \\
\hline & $(7.68)$ & $(6.88)$ & $(4.88)$ \\
\hline \multirow[t]{2}{*}{ total household wealth ${ }^{2}$ (million\$) } & $-0.0872^{* * *}$ & $-0.0798^{* * *}$ & $-0.0598^{* * *}$ \\
\hline & $(-6.26)$ & $(-5.75)$ & $(-4.38)$ \\
\hline \multirow[t]{2}{*}{ current job tenure } & $0.00208^{* * *}$ & $0.00245^{* * *}$ & $0.00176^{* * *}$ \\
\hline & $(9.87)$ & $(11.60)$ & $(8.36)$ \\
\hline \multirow[t]{2}{*}{ self-employed } & $-0.0561^{* * *}$ & $-0.0609^{* * *}$ & $-0.0362^{* * *}$ \\
\hline & $(-9.83)$ & $(-10.99)$ & $(-5.96)$ \\
\hline \multirow[t]{2}{*}{ no. of years worked } & -0.000211 & -0.000265 & -0.000135 \\
\hline & $(-0.79)$ & $(-0.99)$ & $(-0.50)$ \\
\hline \multirow[t]{2}{*}{ individual earnings (hundreds of thousands $\$$ ) } & $-0.0286^{* *}$ & -0.00379 & 0.00117 \\
\hline & $(-2.99)$ & $(-0.39)$ & $(0.12)$ \\
\hline Observations & 22,578 & 22,578 & 21,337 \\
\hline
\end{tabular}

Marginal effects; $t$ statistics in parentheses

Omitted category: works in column (1), works full time in column (2) and (3).

${ }^{*} p<0.05,{ }^{* *} p<0.01,{ }^{* * *} p<0.001 \quad 28$ 